\title{
PEDAGOGIA DA ALTERNÂNCIA NO IF BAIANO CAMPUS SANTA INÊS: UMA PROPOSTA QUE DEU CERTO
}

\author{
N. C. NASCIMENTO ${ }^{1}$ e N.B. FERREIRA COSTA ${ }^{2}$ \\ Instituto Federal de Educação, Ciência e Tecnologia Baiano (Campus Santa Inês) \\ nelian.nascimento@si.ifbaiano.edu.br ${ }^{1}$; nivia.costa@si.ifbaiano.edu.br ${ }^{2}$
}

Artigo submetido em outubro/2012 e aceito em dezembro/2012

DOI: $10.15628 /$ rbept.2012.3494

\section{RESUMO}

Este artigo se propõe a apresentar análises e reflexões acerca da Pedagogia da Alternância, desenvolvida numa turma do Programa de Integração da Educação Profissional ao Ensino Médio na Modalidade de Educação de Jovens e Adultos - PROEJA, no Instituto Federal de Educação Ciência e Tecnologia Baiano, Campus Santa Inês, no município baiano de Santa Inês. Neste trabalho, adota-se o estudo de caso com 26 atores socais, e, como instrumentos de coleta de dados: entrevista e questionário semiestruturado. Utiliza-se também como metodologia, a análise de documentos institucionais. Como referencial teórico, aplica-se a Educação do Campo com ênfase na Metodologia da Alternância. Evidencia-se que a proposta da Pedagogia da Alternância, mostra-se como uma importante alternativa por possibilitar aos sujeitos do campo o fortalecimento da troca de saberes. Neste sentido, o IF Baiano Campus Santa Inês avança ao garantir para os jovens e adultos o caráter popular de uma política social que possibilita ao sujeito do campo e com distorção idade $x$ série, ser incluído em um curso de educação profissional sem se desvincular do seu contexto, da sua cultura, de seu valor e de sua maneira de ver e se relacionar com o ambiente.

PALAVRAS-CHAVE: Educação de Jovens e Adultos, Pedagogia da Alternância, Troca de Saberes, Educação do Campo.

\section{PEDAGOGY OF ALTERNATION IF IN SANTA INES BAIANO CAMPUS: A PROPOSAL GONE RIGHT}

\begin{abstract}
This article intends to present analyzes and reflections on the Pedagogy of Alternation, developed a class Integration Program of Vocational Education to High School in the Youth and Adult Education Mode - PROEJA at the Federal Institute of Education Science and Technology Baiano, Campus St. Agnes, in the Bahia municipality of Santa Ines.. In this work, to adopt the case study with 26 social actors, and as instruments of data collection: interviews and semi-structured questionnaire. It is also used as a methodology, the analysis of institutional documents. The theoretical framework
\end{abstract}

applies to education field with emphasis on the methodology of Alternation. It is evident that the proposal of the Pedagogy of Alternation, shows up as an important alternative for enabling the subject field to strengthen the exchange of knowledge. In this sense, IF Baiano Campus Saint Agnes advances to ensure for young people and adults the popular character of a social policy that enables the subject field and distortion age $x$ number be included on a professional education course without unlink your context of their culture, of their value and their way of seeing and relating to the environment.

KEYWORDS: Youth and Adult Education, Pedagogy of Alternation, Knowledge Exchange and Rural Education. 


\section{INTRODUÇÃO}

Este artigo tem por objetivo apresentar análises e reflexões preliminares, acerca da Pedagogia da Alternância, uma metodologia pedagógica, aplicada numa turma do curso Técnico em Agropecuária Integrado ao Ensino Médio, na modalidade de educação de jovens e adultos, através do Programa Nacional de Integração da Educação Profissional com o Ensino Médio com a Educação Básica, PROEJA, no Instituto Federal de Educação Ciência e Tecnologia Baiano, Campus Santa Inês.

O IF Baiano Campus Santa Inês, foi criado pela Lei no 11.892 de 29 de dezembro de 2008 e consolidado como instituição, a partir da integração das Escolas Agrotécnicas Federais da Bahia e das Escolas Médias de Agropecuária Regional da Comissão Executiva do Plano da Lavoura Cacaueira, antigas EMARCs. A instituição oferta cursos de educação profissional de nível médio, desde o ano de 1996 e passou a ofertar também cursos de Educação Superior, em 2010.

A metodologia pedagógica da Alternância foi uma experiência inédita no Campus Santa Inês e também no Instituto Federal de Educação, Ciência e Tecnologia Baiano, uma instituição ainda por se consolidar, uma vez que possui apenas 7 anos de existência enquanto instituto.

A escolha da metodologia pedagógica, proposta para o curso, pautou-se no público a ser atendido, jovens e adultos, pequenos agricultores e filhos de pequenos agricultores, oriundos de comunidades rurais dos municípios baianos de Ubaíra e Brejões, pertencentes ao Território de Identidade do Vale do Jiquiriçá e que demandavam uma formação profissional técnica voltada para a agricultura familiar e para os princípios que norteiam a Educação do Campo.

O presente texto, assim, vem resultar dos olhares da equipe pedagógica e social do Campus Santa Inês, sobre a turma, por considerar que dentre as experiências em educação de jovens e adultos ofertadas pelo campus, esta é a que registrou o maior alto índice de desempenho acadêmico e o mais baixo índice de evasão. Desta forma, as análises e reflexões a serem propostas neste estudo resultam de questionamentos sobre os principais elementos que contribuíram para que esta turma de educação de jovens e adultos chegasse ao final com índices tão animadores de desempenho acadêmico e a sensação de dever cumprido, por parte da instituição.

O artigo teve como metodologia o estudo de caso e, como instrumentos de coleta de dados: entrevista dirigida aos estudantes do curso e aos docentes, questionário semiestruturado e análise de documentos. As análises e reflexões, para a escrita do presente texto resultaram de entrevistas realizadas com os sujeitos da pesquisa, observação e análise de documentos sobre a Pedagogia da Alternância, Educação do Campo, Educação de Jovens e Adultos, no âmbito do PROEJA e o Projeto Pedagógico do Curso Técnico em Agropecuária Integrado ao Ensino Médio, na modalidade de Educação de Jovens e Adultos.

\section{EDUCAÇÃO DO CAMPO- ALGUMAS CONSIDERAÇÕES}

Sabe-se que nas últimas décadas está sendo escrita, pesquisada e refletida uma nova etapa na história da educação do campo dos brasileiros. Arroyo, Caldart e Molina (2011) apresentam seis pontos marcantes que sinalizam uma trajetória sobre o direito a uma educação do campo: em primeiro lugar, o movimento social por uma educação do campo nasce para denunciar o silenciamento, esquecimento e até o desinteresse sobre o rural nas pesquisas sociais; em segundo 
lugar, o próprio clamor da terra exige uma mudança de postura, pois se torna urgente ouvir e entender a dinâmica social, cultural e educativa dos diferentes grupos que formam o povo do campo; em terceiro lugar, é preciso ressuscitar os direitos usurpados e negados dos povos do campo, pois a escola do meio rural passou a ser tratada como resíduo do sistema educacional, e as políticas sociais não chegaram a incluir as pessoas do campo como sujeito de direitos; em quarto lugar, por muito tempo a visão que prevalece na sociedade é a de que o campo é um lugar atrasado, inferior e arcaico, e a educação do campo nasce de um outro olhar sobre o papel do campo em um projeto de desenvolvimento; em quinto lugar, surge o direito à escolarização ressignificado e reposto com maior abrangência e urgência e a escola legalmente passa a vivenciar uma dinâmica social e cultural do campo e seus movimentos sociais; e, em sexto e último lugar, a defesa das políticas públicas de educação do campo aparece como consciência do direito de diferentes sujetos do campo, dos seus contextos, das suas culturas, de seus valores, das suas maneiras de ver e se se relacionar com o ambiente.

Neste sentido, os autores afirmam que:

"Fazer do povo do campo e dos seus processo de formação o ponto de partida para a formulação de políticas púbicas educativas significa garantir o caráter popular destas políticas e sua articulação com um projeto de país e de campo." (ARROYO, CALDART \& MOLINA: 2011, pág 15)

Por isso, a educação do campo precisa ser específica e diferenciada, ou seja, alternativa. Isto implica que ela deve atender as diferenças históricas e culturais das pessoas que habitam e trabalham no campo. Assim, esta educação requer:

Políticas que afirmem uma visão positiva do campo frente à visão ainda dominante do campo como forma de vida em extinção - Políticas de formação articuladas a políticas públicas de garantia de direitos[...] direito dos povos dos campos: direito à terra, vida, cultura, identidade, memória, educação; - Políticas de formação sintonizadas com a dinâmica social do campo. (ARROYO: 2007, p.173 e 174)

O texto preparatório da Primeira Conferência Nacional "Por uma Educação Básica do Campo" registra:

\footnotetext{
“Nosso propósito é conceber uma educação básica do campo, voltada aos interesses e ao desenvolvimento sociocultural e econômico dos povos que habitam e trabalham no campo, atendendo às suas diferenças históricas e culturais." (ARROYO, CALDART \& MOLINA: 2011, p 27).
}

Neste intuito, não basta ter escolas no campo, mas é preciso construir escolas do campo, ou seja, escolas com um projeto político-pedagógico vinculado às causas, aos desafios, aos sonhos, à história e à cultura do povo trabalhador do campo, registra o referido documento. E mais ainda, uma escola do campo não precisa ser uma escola agrícola, mas será uma escola vinculada à cultura que se produz por meio de relações sociais mediadas pelo trabalho na terra.

Desta forma pressupõe-se que para o alcance de objetivos propostos para a educação do campo necessário se faz utilizar uma proposta metodológica que atenda as diferenças históricas e culturais das pessoas que habitam e trabalham no campo. 


\section{A ALTERNÂNCIA COMO POSSIBILIDADE PARA A EDUCAÇÃO DO HOMEM DO CAMPO}

A Pedagogia da Alternância é uma proposta diferenciada e alternativa que se constitui no universo pedagógico como sendo uma pedagogia da resistência cultural em relação à forte hegemonia neoliberal presente na educação brasileira, principalmente, a partir da década de 90 em diante (NASCIMENTO, 2003). Ela surge como uma proposta metodológica altamente viável para o meio rural, com a qual se consolida uma prática de profundo respeito às características da vida no campo, rompendo com a distância entre o cotidiano dos estudantes e a prática pedagógica escolar.

Alternância significa o processo de ensino-aprendizagem que acontece em espaços e territórios diferenciados e alternados. O primeiro é o espaço familiar e a comunidade de origem (realidade); em segundo, a escola onde o educando(a) partilha os diversos saberes que possui com os outros atores e reflete-se sobre eles em bases científicas (reflexão); e, por fim, retorna-se à família e à comunidade a fim de continuar a práxis (prática + teoria) seja na comunidade, na propriedade (atividades de técnicas agrícolas) ou na inserção em determinados movimentos sociais.

Segundo Caldart (2009) esta proposta metodológica brota do desejo de não cortar raízes e busca integrar a escola do campo com a família e a comunidade do estudante. Esta metodologia possui dois momentos distintos: 1. Tempo Escola: onde os estudantes têm aulas teóricas e práticas, participam de inúmeros aprendizados, avaliam o processo, participam do planejamento das atividades, vivenciam e aprofundam valores; 2 . Tempo Comunidade: onde os estudantes realizam atividades de pesquisa na sua realidade, de registro desta experiência, de prática que permitem a troca do conhecimento nos vários aspectos.

Assim, o Campus Santa Inês, tendo em vista o público para o atendimento, jovens e adultos pertencentes a comunidades rurais, adotou a Pedagogia da Alternância, como proposta metodológica, para embasar a proposta curricular do curso Técnico Integrado ao Ensino Médio na modalidade da educação de jovens e adultos, na perspectiva do PROEJA.

\section{A PEDAGOGIA DA ALTERNÂNCIA NO CAMPUS SANTA INÊS}

\subsection{Como tudo começou}

A Pedagogia da Alternância como proposta de metodologia no Curso Técnico em Agropecuária Proeja, foi adotada no Campus Santa Inês e de forma inédita no Instituto Federal Baiano, no ano de 2012, em função de resposta a uma demanda apresentada para formação técnica a jovens e adultos do campo.

A vocação agrária da instituição, tornava-a referência para os agricultores, pequenos agricultores e organizações governamentais e não-governamentais, na busca por qualificação técnica, bem como por ações de extensão rural. Neste contexto, representantes de comunidades rurais do território do Vale do Jiquiriçá, por vezes se apresentavam solicitando da instituição uma proposta de formação técnica que pudesse qualificar e certificar os trabalhadores rurais inseridos naquela região. 
O perfil apresentados por estes trabalhadores era o de jovens e adultos, pertencentes a comunidades rurais dos municípios de Brejões e Ubaíra, em busca de formação que contribuísse para elevação da escolaridade e acesso a conhecimentos que os auxiliasse no desenvolvimento da agricultura familiar de forma sustentável, sem que precisassem se afastar das suas comunidades.

Para o campus Santa Inês, um desafio estava lançado, em virtude da falta de experiência no atendimento a demandas específicas, como a que se apresentava. Embora a oferta de cursos na modalidade de jovens e adultos, nenhum deles atendeu eminentemente sujeitos do campo.

Esta situação fez com que a instituição buscasse experiências exitosas em educação do campo. Feitos os devidos contatos, a equipe pedagógica do campus, juntamente com professores do núcleo tecnológico participou de um grupo de trabalho responsável pelo estudo e elaboração de uma proposta metodológica que pudesse dar conta de atender a jovens e adultos do campo, visando a profissionalização e respeitando a sua identidade.

Corroborando com Arroyo, Caldart \& Molina, 2011, p 27 pode-se afirmar que:

“Nosso propósito é conceber uma educação básica do campo, voltada aos interesses e ao desenvolvimento e econômico dos povos que habitam e trabalham no campo, atendendo às suas diferenças históricas e culturais".

Assim, o campus Santa Inês buscou elaborar uma proposta pedagógica que atendesse às diferenças históricas e culturais das pessoas que habitavam e trabalhavam no campo, público-alvo da demanda que se apresentava. E considerando a literatura sobre o assunto, bem como as experiências em instituições que trabalhavam com educação do campo a Pedagogia da Alternância foi escolhida para embasar a proposta curricular do curso Técnico em Agropecuária na modalidade PROEJA.

\subsection{A Organização da Proposta Curricular}

De acordo com o Proposta Pedagógica do Curso Técnico em Agropecuária Integrado ao Ensino Médio, na modalidade da Educação de Jovens e Adultos -PROEJA/Alternância, o objetivo geral deste curso é "contribuir para a formação de profissionais comprometidos com o desenvolvimento econômico, social, ambiental, político e cultural de suas comunidades, voltado para a agricultura familiar e para os princípios que norteiam a Educação do Campo." (IFBAIANO: 2012).

Assim, a estrutura curricular do curso desenvolveu-se na modalidade semipresencial, não seriada, organizada em uma semana de Tempo Escola e uma semana de Tempo Comunidade, com ênfase na Troca de Saberes dos sujeitos dos campos com os docentes, conforme preconiza a Pedagogia da Alternância.

Dentro da perspectiva da Troca de Saberes, as ações realizadas tanto no Tempo Escola como no Tempo Comunidade foram planejadas tendo em vista um tema gerador correspondente a cada um dos quatro módulos: 1. Identidades, Cultura e Cidadania; 2. Meio Ambiente e Sustentabilidade; 3. Organização Social e Políticas Públicas; 4. Trabalho e Economia Solidária. Cada módulo quando cursado com aproveitamento prevê uma saída intermediária com certificação de qualificação técnica. 
Para o desenvolvimento destes temas geradores, utilizou-se as seguintes ferramentas pedagógicas: plano de estudo, caderno de realidade, colocação em comum |(estratégia de socialização de pesquisa), tutoria individual, visitas técnicas, serões, visitas as famílias/ comunidades e cursos de formação complementar.

Essas ferramentas pedagógicas serviram também como instrumentos para a avaliação da aprendizagem que se deu de forma contínua e processual, caminhando junto com as ações desenvolvidas pela Pedagogia da Alternância. Este ainda curso prevê como condição obrigatória para obtenção de diploma de conclusão a realização de 150 horas de estágio curricular supervisionado.

\title{
4.3 Um olhar sobre a Pedagogia da Alternância na perspectiva dos estudantes
}

Considerando a importância do olhar dos estudantes sobre o curso sobre e em particular sobre a experiência da Metodologia da Alternância, aplicou-se um questionário semiestruturado,

Perguntados sobre o Tempo Escola, os atores sociais enfatizaram como aspectos positivos: 1. Assistência Estudantil com refeitório, alojamento e auxílios financeiros; 2. Acesso as Tecnologias; 3. Qualidade dos conteúdos trabalhados pelos docentes; 4. Valorização dos conhecimentos trazidos pelos estudantes. E, como aspectos negativos: 1 . Aulas com conteúdos repetidos. 2. Horários vagos; 3. Constante mudança dos locais de sala; 4. Rotatividade de professores.

Sobre o Tempo Comunidade, destacaram como ponto positivo o "Dia de Campo" supervisionado pelo coordenador do curso, como positivo, uma vez que puderam transmitir conhecimentos reelaborados para as suas comunidades. No entanto ressaltaram como ponto negativo a ausência dos professores no acompanhamento dessas atividades.

Consultados sobre a Troca de Saberes, cujo objetivo maior foi possibilitar a reflexão sobre a práxis dos sujeitos envolvidos no processo de ensino e aprendizagem, de modo que pudessem apontar as suas impressões e os possíveis entraves que tenha impossibilitado ou dificultado o referido processo, verificou-se, de acordo com o gráfico 1 que enquanto $11 \%$ concluiu que a ausência dos professores no tempo comunidade prejudicou a troca de saberes, $89 \%$ dos estudantes ressaltou que não desconsideram a importância da presença dos docentes neste momento, mas acreditam que ainda assim a troca de saberes foi possível, uma vez que os seus conhecimentos foram valorizados, a partir do respeito às experiências e vivências que já possuíam enquanto sujeitos do campos.

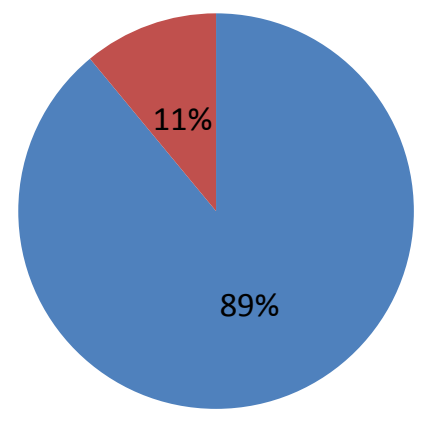

\author{
OCORRE SIM, POIS OS PROFESSORES ESTÃO \\ VALORIZANDO O CONHECIMENTO DOS \\ ESTUDANTES \\ A AUSÊNCIA DE PROFESSORES NO TEMPO \\ COMUNIDADE ACABA PREJUDICANDO A \\ TROCA DE SABERES
}

GRÁFICO 1 - TROCA DE SABERES

Figura 1: Troca de saberes na metodologia da alternância. 


\section{CONCLUSÃO}

O objetivo deste trabalho foi analisar a relevância da implantação da Pedagogia da Alternância em um curso profissional na modalidade de Educação de Jovens e Adultos - Proeja, no IF Baiano Campus Santa Inês.

Neste sentido, percebeu-se que esta proposta metodológica conseguiu contemplar, não apenas conceitualmente, mas filosoficamente, três propostas de alta complexidade em uma política de enfrentamento da questão social: Educação do Campo, Educação de Jovens e Adultos e Educação Profissional.

Pode-se considerar que esta experiência deu certo exatamente pela escolha da proposta da metodologia utilizada, diferenciada e alternativa para um público diferenciado, neste caso, para os sujeitos do campo, atendendo às suas diferenças históricas e culturais. Consequentemente, esta foi a única turma de educação de jovens e adultos na modalidade PROEJA a apresentar baixo índice de evasão e elevado índice de aprovação, conclusão e inserção na área de formação.

Sabe-se que na atualidade o fortalecimento destes três campos teóricos é uma realidade e neste contexto a Metodologia da Alternância surge como elo para reparar, equalizar e qualificar um projeto que tem todas as perspectivas possíveis para dar certo, ressalvadas as problemáticas identificadas pelos sujeitos envolvidos.

Neste sentido, o IF Baiano Campus Santa Inês avança ao garantir para os jovens e adultos o caráter popular de uma política social que possibilita ao sujeito do campo e com distorção idade $\mathrm{x}$ série, ser incluído em um curso de educação profissional sem se desvincular do seu contexto, da sua cultura, de seu valor e de sua maneira de ver e se relacionar com o ambiente em que está inserido.

\section{REFERÊNCIAS}

1. ANDRADE, Maria Margarida de. Introdução à Metodologia do Trabalho Científico. 5a ed. São Paulo: Editora Atlas, 2001.

2. ARROYO, Miguel G. Políticas de formação de educadores do campo. In: Cadernos CEDES, Campinas. V. 27, p. 157-176. Maio/Agosto. 2007.

3. ARROYO, Miguel G; CALDART, Roseli Salete; e, MOLINA, Mônica Castagna. (orgs ). Por uma Educação do Campo. 5a ed. Petrópolis, RJ:Vozes, 2011.

4. BRASIL. Diretrizes Operacionais para a Educação Básica do Campo. (RESOLUÇÃO CNE/CEB 1, 03/04/2002)

5. . Decreto 5.840, de 13 de julho de 2006.

6. . Documento Base do Proeja. Brasília. 2006.

7. CALDART, Roseli Salete. A Escola do Campo em Movimento. In: ARROYO, Miguel Gonzalez; CALDART, Roseli Salete; MOLINA, Mônica Castagna. (Org.). Por uma educação do Campo. 4ạ ed. Petrópolis RJ: Vozes, 2009.

8. COSTA, Nívia B. F. Assistência Estudantil e Evasão Escolar no PROEJA do CEFET-BA/Sede. 2008. (Monografia). Especialização em CEPROEJA. CEFET-BA, [OUT/2008] 
9. DEMO, Pedro. Pesquisa: princípio científico e educativo. São Paulo: Cortez. 1991.

10. GIL, Antonio Carlos. Métodos e Técnicas de Pesquisa Social. 5ạ ed. São Paulo: Editora Atlas, 2007.

11. IFBAIANO. Plano de Desenvolvimento Institucional. 2009.

12. IFBAIANO. Relatório PROEJA ALTERNÂNCIA. 2012.

13. IFBAIANO. Projeto Pedagógico de Curso. Técnico em Agropecuária Integrado ao Ensino Médio na Modalidade de Educação de Jovens e Adultos / PROEJA na Metodologia da Alternância. 2012 